\title{
PERENCANAAN ARSITEKTUR SISTEM TERINTEGRASI DENGAN MENGGUNAKAN TOGAF ADM (Studi kasus: Yayasan Pendidikan Rosma)
}

\author{
${ }^{1}$ Arif Maulana Yusuf, ${ }^{2}$ Budi Permana \\ E-mail : arif@rosma.ac.id, budi-permana@live.com
}

\begin{abstract}
Abstrak
Strategi yang penting untuk menghadapi perkembangan teknologi yaitu dengan memanfaatkan dan meningkatkan dukungan dalam sistem informasi untuk enterprise. Yayasan Pendidikan Rosma (Yaperos) melakukan aktivitas organisasinya selalu mengarah kepada kepuasan para pengguna jasa pendidikan disetiap lembaga pendidikan yang ada dalam naungan Yayasan disesuaikan dengan visi dan misi. Untuk mendukung aktivitas tersebut diperlukan sebuah paradigma untuk merencanakan, merancang dan mengelola suatu sistem yang disebut arsitektur enterprise. Dalam melakukan perencanaan enterpise arsitektur diperlukan metodologi yang lengkap dan mudah saat digunakan, TOGAF ADM adalah metodologi yang cukup lengkap. Dimana tahapan metodologi ini dapat menghasilkan sebuah arsitektur terintegrasi yang dijadikan sebagai bahan acuan blue print oleh yayasan untuk mencapai tujuan strategis.
\end{abstract}

Kata kunci : arsitektur, enterprise, TOGAF-ADM, cetak biru, yayasan

\section{Abstract}

An important strategy for dealing with technological developments is by utilizing and increasing support in information systems for the enterprise. The Rosma Education Foundation (Yaperos) conducts its organizational activities always leads to satisfaction of the users of educational services in every educational institution that is in the shade of the Foundation tailored to the vision and mission. To support these activities a paradigm is needed to plan, design and manage a system called enterprise architecture. In implementing architectural planning, a complete and easy methodology is needed when used, TOGAF ADM is a fairly complete methodology. Where this methodology stage can produce an integrated architecture that is used as a blue print reference material by the foundation to achieve strategic objectives.

Keywords : architecture, enterprise, TOGAF-ADM, blueprint, foundation 


\section{Pendahuluan}

Dunia komputer yang semakin berkembang dengan kompleks mendorong setiap individu dan kelompok harus mau menerapkannya dalam setiap aktivitas. Dimana dalam kehidupan modern saat ini, teknologi informasi menjadi suatu bagian yang tidak terpisahkan dari aktivitas bisnis setiap perusahaan. Menurut Kustiyahningsih (2013:2), Sehingga perlunya perencanaan sistem informasi yang melihat dari berbagai macam sudut pandang pengembangan sistem, dimulai dengan mendefinisikan arsitektur bisnis dalam organisasi, mendifinisikan arsitektur data yang di gunakan, mendifinisikan arsitektur aplikasi yang di bangun serta mendefinisikan arsitektur teknologi yang mendukung jalanya sistem informasi.

Menuju sebuah keberhasilan diperlukan keselarasan dalam menerapkan sistem informasi dimana kebutuhan organisasi yang hanya dapat terjawab dengan memperhatikan faktor integrasi dalam pengembangannya, tujuan dari integrasi sebenarnya yaitu agar kesenjangan yang selama ini terjadi pada proses pengembangan sistem dapat berkurang. Dalam menurunkan kesenjangan tersebut diperlukan suatu paradigma dalam perencanaan, perancangan dan pengelolaan sistem informasi yang dinamakan dengan arsitektur enterprise. Terdapat beberapa pilihan metode dan framework untuk digunakan, salahsatunya yaitu TOGAF ADM.

TOGAF merupakan metode yang berisi beberapa aktivitas yang digunakan untuk memodelkan pengembangan arsitektur enterprise, TOGAF memberikan gambaran metode yang lengkap dalam membangun dan mengelola juga mengimplementasikan framework dan sistem yang digunakan untuk menggambarkan sebuah model arsitektur enterprise untuk perusahaan yang dapat dijadikan sebuah rekomendasi pengembangan sistem yang terintegrasi.

Yaperos adalah suatu yayasan yang bergerak pada bidang pendidikan dan berlokasi di Karawang. Dalam menghadapi tantangan bisnis kedepan yang semakin kompetitif, Yaperos telah mencanangkan suatu program peningkatan kinerja bisnis, yang mencakup penyederhanaan proses bisnis, otomasi dan integrasi proses bisnis dengan pemanfaatan teknologi informasi. Sistem informasi yang saat ini terjadi pada Yaperos tidak adanya keterkaitan antara satu bagian dengan bagian yang lainnya yang berdampak bagi yayasan dalam melansanakan kegiatan operasionalnya. Dengan melihat kondisi tersebut sehingga perlu di bangun suatu architecture dengan framework tertentu sebagai solusi kebutuhan dari tiap bagian agar terintegrasi.

\section{Tinjauan Pustaka}

Beberapa teori atau definisi yang berhubungan dengan tesis ini akan diuraikan pada bab ini sesuai dengan metoda yang digunakan.

\section{Enterprise Architecture}

Menurut Bernard (2005:31), "Enterprise adalah suatu area aktivitas dan tujuan dalam satu organisasi atau beberapa organisasi, di mana terdapat pertukaran informasi dan sumber daya lainnya".

Menurut Hadiana (2016:13), “Arsitektur adalah berupa gambaran sebuah struktur Perusahaan/lembaga/institusi yang terdiri dari berbagai macam komponen pendukung dan relasi antar komponen tersebut".

Menurut Minoli (2008:35), "Enterprise Architecture dapat didefinisikan sebagai sebuah blueprint yaitu: Bagaimana semua elemen TI dan manajemen bekerja bersama dalam satu kesatuan dan memberikan gambaran eksplisit mengenai hubungan antara proses manajemen dengan TI yang sekarang dan yang diharapkan. Jika dikaitan dengan enterprise, maka EA harus memberikan strategi yang memungkinkan organisasi mendukung keadaan yang sekarang dan juga bertindak sebagai roadmap menuju lingkungan yang ditargetkan".

\section{TOGAF}

Menurut The Open Group (2009:25), TOGAF dikembangkan oleh The Open Group's Architecture Framework pada tahun 1995. Awalnya TOGAF digunakan oleh Departemen 
Pertahanan Amerika Serikat namun pada perkembangannya TOGAF banyak digunakan berbagai bidang seperti perbankan, industri manufaktur dan juga pendidikan. TOGAF digunakan untuk mengembangkan Enterprise Architecture, dimana terdapat metode dan tools yang detil untuk mengimplementasikannya, hal inilah yang membedakan dengan Framework EA lain misalnya Framework Zachman.

Salah satu kelebihan menggunakan Framework TOGAF adalah karena sifatnya fleksibel dan bersifat open source. TOGAF memberikan metode detil bagaimana membangun dan mengelola serta mengimplementasikan arsitektur enterprise dan sistem informasi yang disebut dengan Architecture Development Method (ADM).

Menurut The Open Group (2009:35), TOGAF ADM seperti ditunjukkan pada Gambar 1, juga merupakan metode yang fleksibel yang mengantifikasi berbagai macam teknik pemodelan yang digunakan dalam perancangan, dimana metode ini bisa disesuaikan dengan perubahan dan kebutuhan selama perancangan dilakukan TOGAF ADM juga menyatakan visi dan prinsip yang jelas bagaimana melakukan pengembangan arsitektur enterprise, prinsip tersebut digunakan sebagai ukuran untuk menilai keberhasilan dari pengembangan arsitektur enterprise oleh organisasi, prinsip-prinisip tersebut dapat dijelaskan sebagai berikut:

1. Prinsip Enterprise

Pengembangan arsitektur yang dilakukan diharapkan mendukung seluruh bagian organisasi, termasuk unit-unit organisasi yang membutuhkan.

2. Prinsip Teknologi Informasi (TI)

Lebih mengarahkan konsistensi penggunaan TI pada seluruh bagian organisasi, termasuk unit-unit organisasi yang akan menggunakan.

3. Prinsip Arsitektur

Merancang arsitektur sistem berdasarkan kebutuhan proses bisnis dan bagaimana mengimplementasikannya.

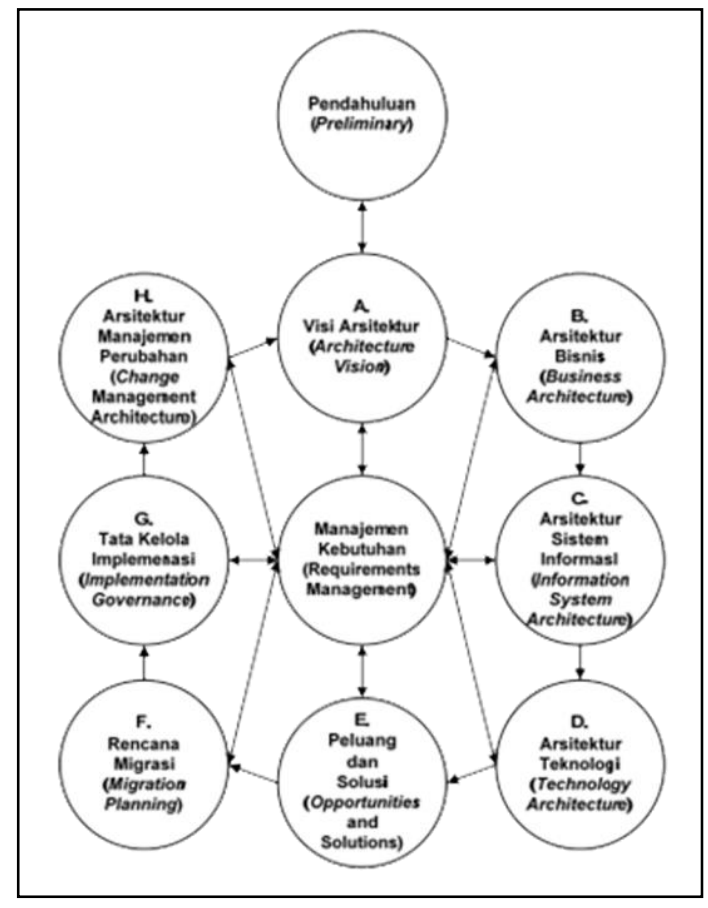

Gambar 1. Fase Architecture Devopment Method (The Open Group, 2009:35)

Menurut The Open Group (2009:50), TOGAF-Architecture Development Method (ADM) merupakan metodologi lojik dari TOGAF terdiri dari delapan fase untuk pengembangan dan pemeliharaan technical architecture dari organisasi. ADM membentuk sebuah siklus yang iteratif untuk keseluruhan proses, antar fase, dan dalam tiap fase di mana tiap-tiap iterasi keputusan baru harus diambil. Keputusan tersebut dimaksudkan dalam menentukan luas cakupan enterprise, level kerincian, target waktu yang dicapai dan asset arsitektural yang digali dalam enterprise continuum. ADM merupakan metode yang umum sehingga jika diperlukan pada prakteknya ADM dapat disesuaikan dengan kebutuhan spesifik tertentu, misalnya digabungkan dengan Framework yang lain sehingga ADM menghasilkan arsitektur yang spesifik terhadap organisasi.

\section{Metodologi Penelitian}

Berdasarkan landasan teori yang sudah dipaparkan, maka metodologi penelitian yang 
dilakukan dalam perencanaan arsitektur terintegrasi pada Yaperos berdasarkan langkahlangkah pemikiran kerangka kerja TOGAF ADM, dapat digambarkan sebagai berikut :

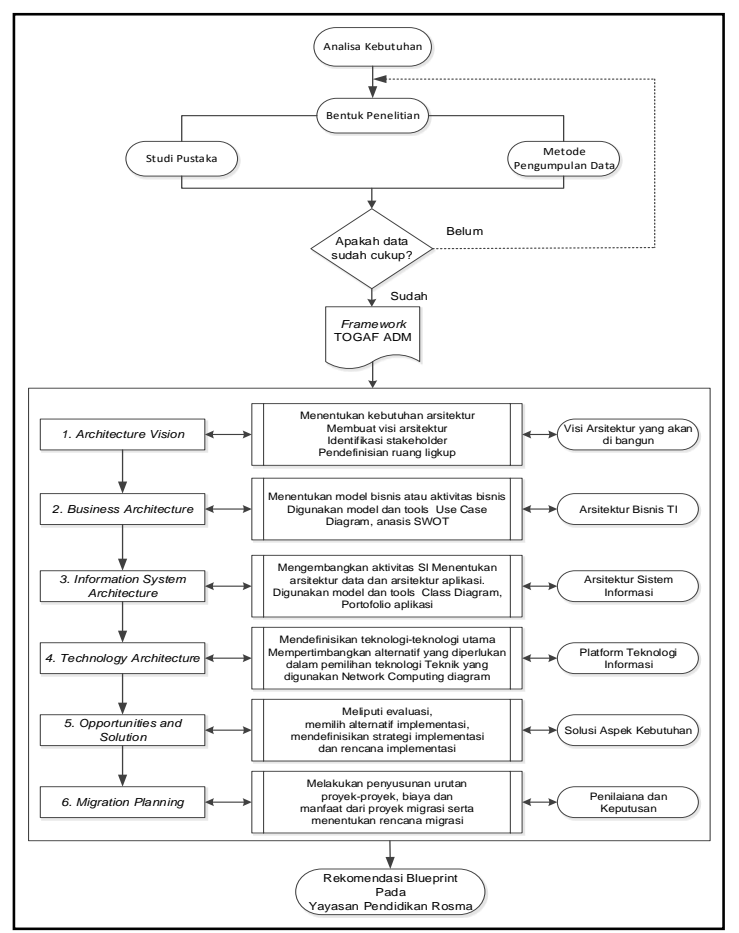

Gambar 2 Metodologi Penelitian

a. Analisa Kebutuhan Sistem

Analisa kebutuhan sistem merupakan tahapan untuk mengetahui kebutuhan dalam pembangunan sistem yang terintegrasi

b. Studi Pustaka

Proses yang dilakukan untuk mencari informasi mengenai teori, metode dan konsep yang sangat relevan dengan permasalahan.

c. Bentuk penelitian

Dilakukan peneliti adalah menggunakan studi kasus dengan objek penelitian pada Yaperos Karawang.

d. Metode Pengumpulan data

Mengumpulkan data dilakukan agar memperoleh informasi yang dibutuhkan dan kecukupan data dalam rangka tercapainya tujuan penelitian.

e. Perencanaan Arsitektur

Dalam pembuatan sebuah blueprint model sistem terintegrasi dapat dilihat dalam tahapan berikut :
(1) Architecture Vision

Pada Tahapan inisiasi merupakan siklus perkembangan arsitektur yang menentukan kebutuhan arsitektur, Membuat visi arsitektur, Identifikasi stakeholder, dan pengajuan persetujuan sehingga dapat memulai pengembangan arsitektur.

(2) Business Architecture

Tahapan ini penentu model dalam bisnis atau aktivitas pada bisnis yang diinginkan disesuaikan dengan skenario bisnis, selain itu juga mencakup pengembangan arsitektur bisnis sehingga dapat mendukung visi arsitektur yang sudah disetujui.

(3) Information System Architecture

Dalam tahap ini cukup menekankan bagaimana aktivitas yang ada dalam arsitektur sistem informasi dapat dikembangkan.

(4) Technology Architecture

Tahapan ini mendefinisikan teknologi yang dibutuhkan dalam penyediaan dukungan lingkungan untuk aplikasi berikut data akan dikelola.

(5) Opportunities and Solution

Kegiatan yang dapat dilakukan dalam setiap tahapan meliputi proses evaluasi, pemilihan alternatif implementasi, pendefinisian metode implementasi dan rencana implementasi.

(6) Migration Planning

Dalam tahapan ini dilakukan penyusunan urutan proyek, biaya dan manfaat dari proyek migrasi.

\section{Hasil dan Pembahasan}

Yaperos adalah yayasan yang bergerak pada bidang pendidikan yang berlokasi di Karawang. Untuk menghadapi tantangan bisnis ke depan, Yaperos telah mencanangkan suatu program peningkatan kinerja bisnis yang mencakup penyederhanaan proses bisnis, otomasi dan integrasi proses bisnis dengan model arsitektur sistem terintegrasi dan menggunakan framework. 
Yaperos dalam menerapkan model arsitektur enterprise membaginya menjadi dua bagian yaitu arsitektur teknologi informasi dan arsitektur bisnis seperti yang telihat dalam gambar 3 dimana arsitektur TI sebagai pendukung arsitektur bisnis yang dapat menunjang untuk mencapai tujuan, visi, strategi dari arsitektur enterprise Yaperos. Adapun arsitektur TI meliputi komponen infrastruktur TI, data dan aplikasi sedangkan arsitektur bisnis terdiri dari komponen-komponen kemampuan organisasi, keadaan organisasi serta proses bisnis dan informasi.

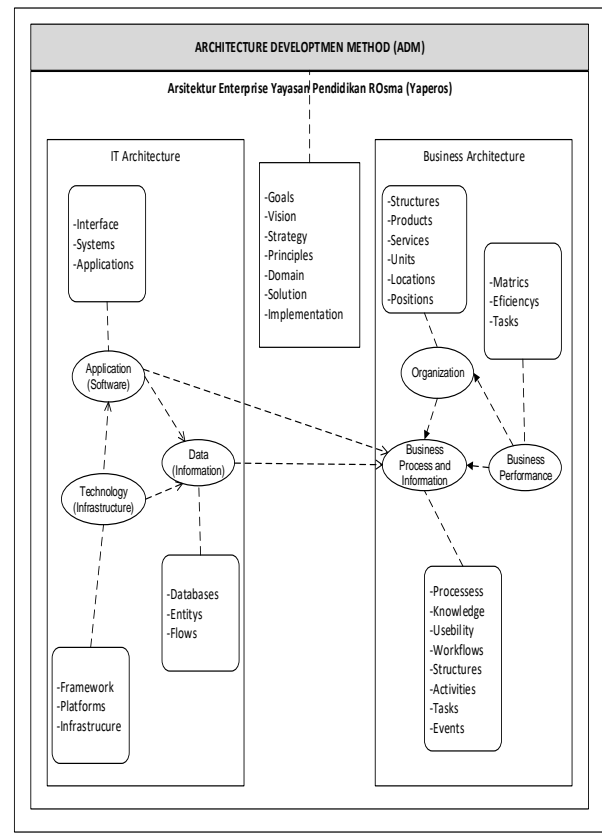

Gambar 3 Model Prinsip Arsitektur Enterprise Yayasan Pendidikan Rosma

Aktivitas bisnis Yayasan Pendidikan Rosma (Yaperos) dapat didefinisikan menjadi dua aktivitas yaitu utama dan pendukung.

a. Aktivitas utama yaitu suatu kegiatan penerimaan siswa atau mahasiswa baru, proses pelayanan, proses pengelolaan alumni dan proses promosi. Terdiri dari :

1) Penerimaan siswa atau mahasiswa baru

Proses pengambilan dan pengisian formulir pendaftaran, pembayaran uang pendaftaran serta mengikuti seleksi masuk yang dilaksanakan oleh pihak panitia.

2) Sarana dan Prasarana
Proses pengelolaan dan perencanaan yang ada.

3) Pengelolaan alumni

Proses melakukan pendataan alumni serta agar jalinan komunikasi terhadap alumni dapat terus terjaga dan adanya informasi yang di berikan oleh alumni.

4) Promosi

Proses perencanaan dan penyampaian atau pengarahan tentang keunggulan yang dimiliki agar pengguna jasa pendidikan menjadi tertarik.

b. Aktivitas pendukung yaitu kegiatan yang mendukung pembuatan value dari aktivitas utama. Terdiri dari :

1) Keuangan

Proses pengelolaan keuangan atau pembiayaan, melakukan perencanaan keuangan, akuntansi umum atau anggaran atau biaya dan penggajian.

2) Kepegawaian

Proses perencanaan pegawai, penerimaan pegawai, administrasi pegawai dan penggajian, absensi dan pemutusan hubungan kerja.

3) Pengadaan Barang

Kegiatan yang dilakaukan yaitu proses perminintaan pembelian barang, melakukan order barang dan penerimaan barang.

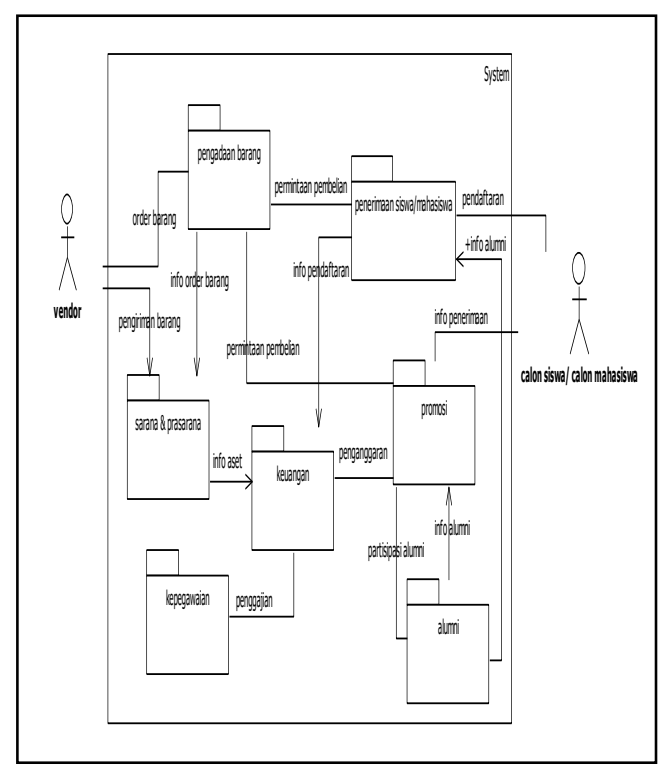

Gambar 4. Diagram Package Bisnis Proses Yayasan Pendidikan Rosma 
Berdasarkan arsitektur yang sudah terbentuk, maka Yaperos perlu mendapatkan entitas untuk mencoba menggambarkan keterhubungannya. Dengan penggunaan gambaran dimana proses bisnis dalam organisasi dilakukan sehingga entitas data perlu diturunkan. Berikut beberapa entitas pada fungsi bisnis Yaperos yang ditunjukan sebagai berikut :

Tabel 1 Kandidat Entitas Data

\begin{tabular}{|c|c|c|}
\hline No & $\begin{array}{c}\text { Entitas Fungsi } \\
\text { Bisnis }\end{array}$ & Entitas Data \\
\hline 1 & $\begin{array}{l}\text { Penerimaan } \\
\text { Siswa/mahasiswa } \\
\text { Baru }\end{array}$ & $\begin{array}{l}\text { 1. Entitas } \\
\text { Perencanaan } \\
\text { PMB } \\
\text { 2. Entitas Jadwal } \\
\text { PMB } \\
\text { 3. Entitas } \\
\text { Pendaftaran } \\
\text { 4. Entitas } \\
\text { Penilaian } \\
\text { 5. Entitas Panitia }\end{array}$ \\
\hline 2 & $\begin{array}{l}\text { Sarana dan } \\
\text { Prasarana }\end{array}$ & $\begin{array}{l}\text { 6. Entitas } \\
\text { Perencanaan } \\
\text { Sarana dan } \\
\text { Prasarana } \\
\text { 7. Entitas } \\
\text { Pengadaan } \\
\text { 8. Entitas } \\
\text { Inventarisasi } \\
\text { Aset } \\
\text { 9. Entitas } \\
\text { Lembaga } \\
\text { Pendidikan } \\
\end{array}$ \\
\hline 3 & $\begin{array}{l}\text { Pengelolaan Data } \\
\text { Alumni }\end{array}$ & $\begin{array}{l}\text { 10.Entitas Data } \\
\text { Alumni } \\
\text { 11.Entitas Berita } \\
\text { Alumni } \\
\text { 12. Entitas } \\
\text { Patisipasi } \\
\text { Alumni } \\
\text { 13.Entitas Admin }\end{array}$ \\
\hline 4 & Promosi & $\begin{array}{l}\text { 14.Entitas } \\
\text { Perencanaan } \\
\text { Promosi } \\
\text { 15.Entitas Jadwal } \\
\text { Promosi } \\
\text { 16.Entitas } \\
\text { Kegiatan } \\
\text { Promosi }\end{array}$ \\
\hline
\end{tabular}

\begin{tabular}{|c|c|c|}
\hline No & $\begin{array}{c}\text { Entitas Fungsi } \\
\text { Bisnis }\end{array}$ & Entitas Data \\
\hline & & $\begin{array}{l}\text { 17.Entitas } \\
\text { Anggaran } \\
\text { Promosi } \\
\text { 18.Entitas Panitia }\end{array}$ \\
\hline 5 & $\begin{array}{l}\text { Pengelolaan } \\
\text { Keuangan }\end{array}$ & $\begin{array}{l}\text { 19.Entitas } \\
\text { Perencanaan } \\
\text { Keuangan } \\
\text { 20.Entitas } \\
\text { Penerimaan } \\
\text { Keuangan } \\
\text { 21.Entitas } \\
\text { Pengeluaran } \\
\text { Keuangan } \\
\text { 22.Entitas } \\
\text { Pengalokasian } \\
\text { Keuangan } \\
\text { 23.Entitas } \\
\text { Lembaga } \\
\text { Pendidikan }\end{array}$ \\
\hline 6 & $\begin{array}{l}\text { Pengelolaan } \\
\text { Kepegawaian }\end{array}$ & $\begin{array}{l}\text { 24.Entitas } \\
\text { Perencanaan } \\
\text { kebutuhan } \\
\text { Pegawai } \\
\text { 25.Entitas Data } \\
\text { Pegawai } \\
\text { 26.Entitas } \\
\text { Rekrutmen } \\
\text { Pegawai } \\
\text { 27.Entitas } \\
\text { Penggajian } \\
\text { 28.Entitas } \\
\text { Penilaian } \\
\text { Pegawai } \\
\text { 29.Entitas } \\
\text { Lembaga } \\
\text { Pendidikan } \\
\end{array}$ \\
\hline 7 & Pengadaan Barang & $\begin{array}{l}\text { 30.Entitas vendor } \\
\text { 31.Entitas Order } \\
\text { Barang } \\
\text { 32.Entitas } \\
\text { Penerimaan } \\
\text { Barang } \\
\text { 33.Entitas } \\
\text { Permintaan } \\
\text { Barang } \\
\text { 34.Entitas Bagian }\end{array}$ \\
\hline
\end{tabular}


Arsitektur aplikasi adalah untuk mendefinisikan jenis-jenis dari sistem aplikasi penting untuk melakukan proses data dan pendukung fungsi bisnis yang ada pada Yaperos. Untuk mendefinisikan semua daftar aplikasi yang nantinya dapat digunakan oleh Yaperos. Berikut daftar tiap komponen dan beberapa aplikasi yang nantinya akan digunakan pada Yayasan Pendidikan Rosma (Yaperos) seperti tertera pada tabel 2.

Tabel 2 Katalog Rencana Aplikasi

\begin{tabular}{|c|c|c|c|}
\hline No & Komponen Katalog & Rencana Aplikasi & $\begin{array}{c}\text { Kode } \\
\text { Aplikasi }\end{array}$ \\
\hline 1 & Sistem Informasi PMB & $\begin{array}{l}\text { Perencanaan PMB } \\
\text { Penjadwalan PMB } \\
\text { Pendaftaran PMB } \\
\text { Pengelolaan Nilai Seleksi } \\
\text { Pembuatan Laporan PMB }\end{array}$ & $\begin{array}{l}1.1 \\
1.2 \\
1.3 \\
1.4 \\
1.5\end{array}$ \\
\hline 2 & $\begin{array}{l}\text { Sistem Informasi Manajemen } \\
\text { Sarana dan Prasarana }\end{array}$ & $\begin{array}{l}\text { Perencanaan Sarana dan Prasarana } \\
\text { Pengadaan } \\
\text { Inventarisasi Aset } \\
\text { Pembuatan Laporan Aset }\end{array}$ & $\begin{array}{l}2.1 \\
2.2 \\
2.3 \\
2.4\end{array}$ \\
\hline 3 & $\begin{array}{l}\text { Sistem Informasi Pengelolaan } \\
\text { Data Alumni }\end{array}$ & $\begin{array}{l}\text { Pendataan Alumni } \\
\text { Pemberitaan Alumni }\end{array}$ & $\begin{array}{l}3.1 \\
3.2\end{array}$ \\
\hline 4 & Sistem Informasi Promosi & $\begin{array}{l}\text { Perencanaan Promosi } \\
\text { Penjadwalan Promosi } \\
\text { Pengelolaan Data Panitia Promosi } \\
\text { Pengelolaan Kegiatan Promosi } \\
\text { Pengelolaan Anggaran Promosi }\end{array}$ & $\begin{array}{l}4.1 \\
4.2 \\
4.3 \\
4.4 \\
4.5\end{array}$ \\
\hline 5 & $\begin{array}{l}\text { Sistem Informasi Pengelolaan } \\
\text { Keuangan }\end{array}$ & $\begin{array}{l}\text { Perencanaan Keuangan } \\
\text { Penerimaan Keuangan } \\
\text { Pengeluaran Keuangan } \\
\text { Pengalokasian Keuangan } \\
\text { Pembuatan Laporan Keuangan }\end{array}$ & $\begin{array}{l}5.1 \\
5.2 \\
5.3 \\
5.4 \\
5.5\end{array}$ \\
\hline 6 & $\begin{array}{l}\text { Sistem Informasi Pengelolaan } \\
\text { Kepegawaian }\end{array}$ & $\begin{array}{l}\text { Perencanaan Kepegawaian } \\
\text { Pengelolaan Data Pegawai } \\
\text { Rekrutmen Pegawai } \\
\text { Penilaian Pegawai } \\
\text { Penggajian } \\
\end{array}$ & $\begin{array}{l}6.1 \\
6.2 \\
6.3 \\
6.4 \\
6.5 \\
\end{array}$ \\
\hline 7 & $\begin{array}{l}\text { Sistem Informasi Pengadaan } \\
\text { Barang }\end{array}$ & $\begin{array}{l}\text { Permintaan Pembelian } \\
\text { Order Barang } \\
\text { Penerimaan Barang }\end{array}$ & $\begin{array}{l}7.1 \\
7.2 \\
7.3\end{array}$ \\
\hline
\end{tabular}

Hubungan secara skematik arsitektur aplikasi yang dapat digunakan oleh Yayasan Pendidikan Rosma (Yaperos) akan terlihat pada gambar 5 dibawah ini. 


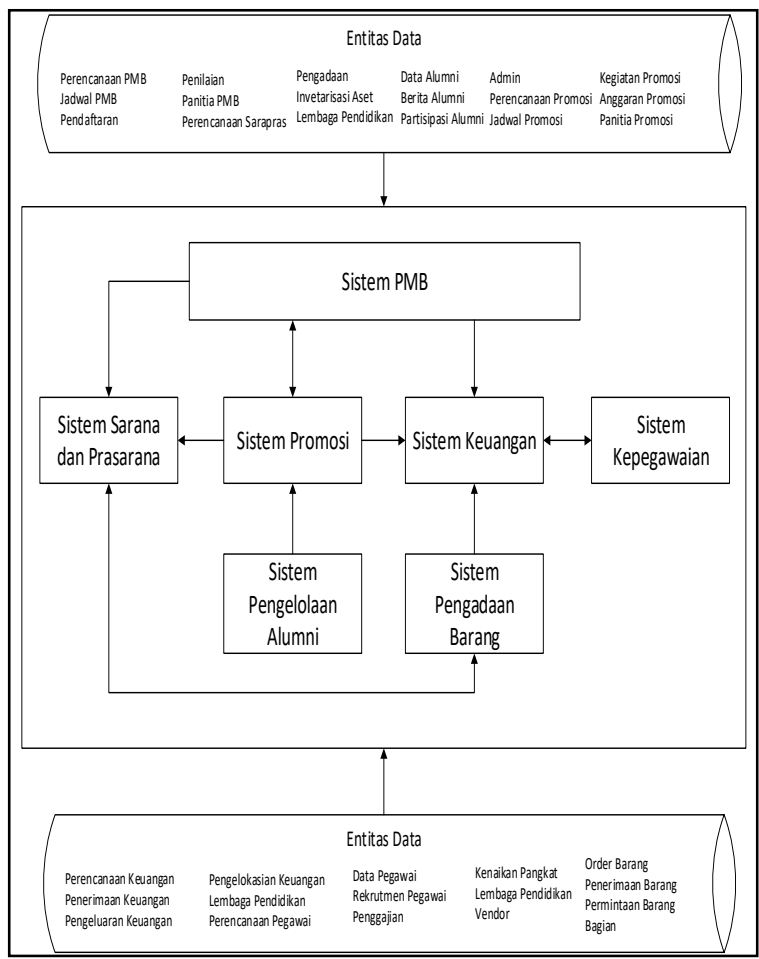

Gambar 5 Skema arsitektur aplikasi

Berikut ini adalah gambaran konfigurasi sistem secara logik (tidak menggambarkan secara fisik jumlah server yg dibutuhkan) :

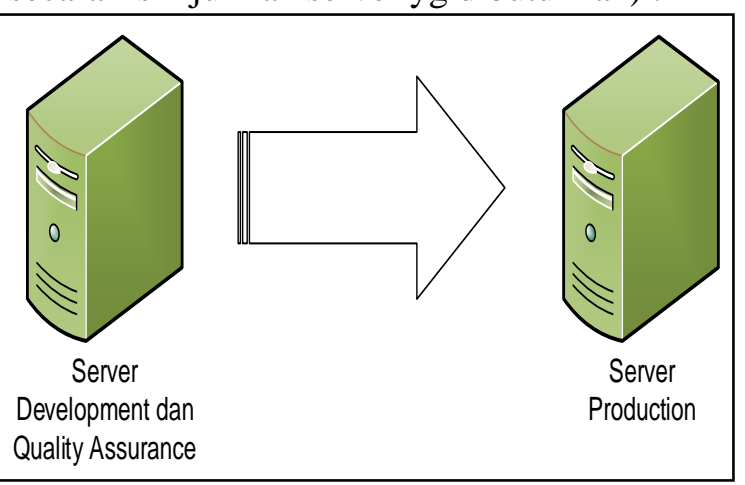

Gambar 6 System Landscape Yayasan

Pendidikan Rosma

Topology Infrastructure dapat diusulkan dengan berdasarkan keragaman pengembangan jaringan serta kondisi yang sudah tersedia terbagi atas dua skema jaringan dengan menggunakan koneksi kabel dan wireless. Berikut Infrastructure topology jaringan Yayasan Pendidikan Rosma :

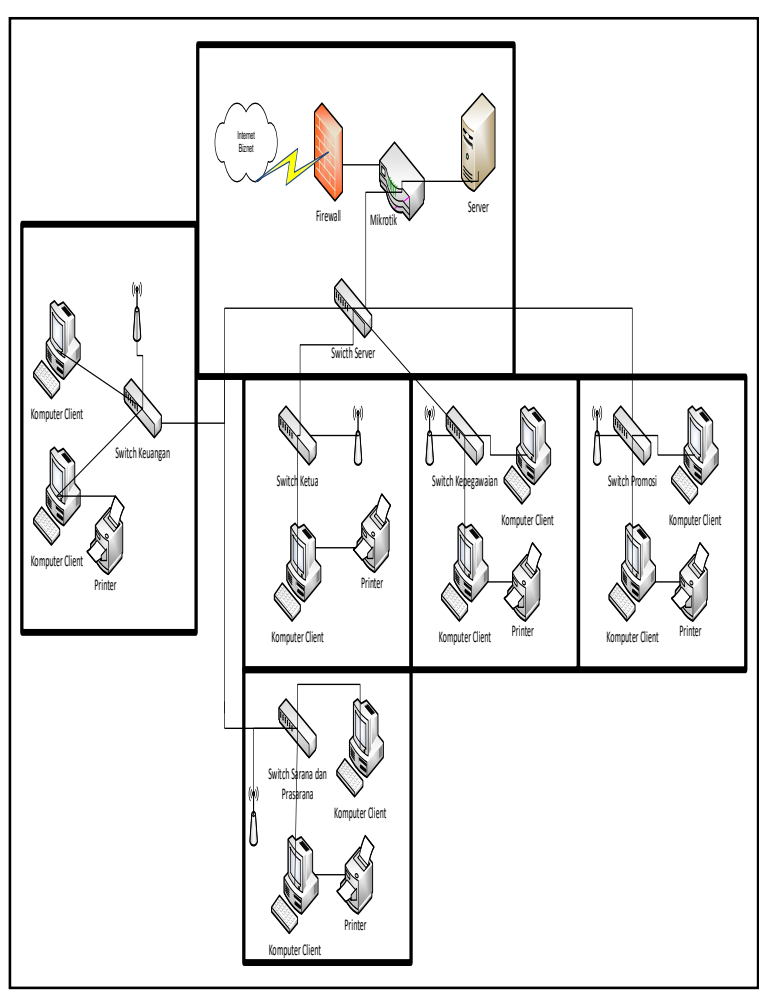

Gambar 7 Infrastructure topology Jaringan Yayasan Pendidikan Rosma

Estimasi jadwal penyelesaian proyek dapat berubah dengan waktu yang lebih lama apabila beberapa atau seluruh asumsi yang disebutkan diatas tidak terpenuhi.

Tabel 4 Matrik Jadwal Pengembangan Aplikasi

\begin{tabular}{|c|c|c|c|c|c|c|c|c|c|}
\hline \multirow{2}{*}{ Wama Aplikasi Nolitu } & \multicolumn{9}{|c|}{ Thenn } \\
\hline & Bn-1 & 8n-2 & $8 \ln 3$ & Bn 4 & Bin-5 & $\operatorname{Bn}-6$ & Bh.7 & Bing & Bn-9 \\
\hline \begin{tabular}{l|l}
1 & Perencanaan PVB \\
\end{tabular} & & & & & & & & & \\
\hline \begin{tabular}{l|l|}
2 & Peniduala \\
\end{tabular} & & & & & & & & & \\
\hline 3 PendediannPUB & & & & & & & & & \\
\hline \begin{tabular}{l|l}
4 & Pengeddaan Fila Seteisi \\
\end{tabular} & & & & & & & & & \\
\hline 5 Perruaban Laourn P16 & & & & & & & & & \\
\hline 6 Perencarazn SaP. & & & & & & & & & \\
\hline \begin{tabular}{|l|l|}
7 & Pengaban \\
\end{tabular} & & & & & & & & & \\
\hline \begin{tabular}{|l|l|l|}
8 & nerriazisasi isset \\
\end{tabular} & & & & & & & & & \\
\hline 9 Pentuatan Lapoan Asef & & & & & & & & & \\
\hline 10 Pencotian Aumi & & & & & & & & & \\
\hline 11 Berita Alumi & & & & & & & & & \\
\hline \begin{tabular}{|l|l|}
12 & Perencanan Prumosi \\
\end{tabular} & & & & & & & & & \\
\hline 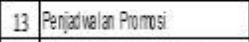 & & & & & & & & & \\
\hline \begin{tabular}{|l|l|}
14 & Pengeddar Dati Pania Promsi \\
\end{tabular} & & & & & & & & & \\
\hline \begin{tabular}{|l|l|}
15 & Pengeddana Keggatan Promos \\
\end{tabular} & & & & & & & & & \\
\hline 16 Pangedaran Angazan Promosi & & & & & & & & & \\
\hline 17 Perencanaan Kevangan & & & & & & & & & \\
\hline \begin{tabular}{|l|l|}
18 & Peneimran Kevangan \\
\end{tabular} & & & & & & & & & \\
\hline 19 Pengeluaran Keuangan & & & & & & & & & \\
\hline 20 Pengadoasian Kevangan & & & & & & & & & \\
\hline
\end{tabular}


Tabel 4 Matrik Jadwal Pengembangan Aplikasi (lanjutan)

\begin{tabular}{|c|c|c|c|c|c|c|c|c|c|}
\hline \multirow{2}{*}{ 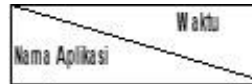 } & \multicolumn{9}{|c|}{ Tahn } \\
\hline & Bnn-1 & $8 n-2$ & Bhis & Bn 4 & Bh-5 & $\operatorname{lin}-6$ & Bh.7 7 & Bhs & Bhas \\
\hline 21 Perrubatian Lapoan Keuangan & & & & & & & & & \\
\hline 22 Petencanaan Kepergauáan & & & & & & & & & \\
\hline 23 Pengedlaan Daba Pegana & & & & & & & & & \\
\hline 24 Relinutren Pegavai & & & & & & & & & \\
\hline \begin{tabular}{l|l|}
25 & Peniban Pegạua \\
\end{tabular} & & & & & & & & & \\
\hline 26 Penggajan & & & & & & & & & \\
\hline 27 Permitian Pertcaian & & & & & & & & & \\
\hline \begin{tabular}{l|l}
28 & Order Baram \\
\end{tabular} & & & & & & & & & \\
\hline \begin{tabular}{|l|l|}
29 & Penemarman Barang \\
\end{tabular} & & & & & & & & & \\
\hline
\end{tabular}

Keberhasilan dari implementasi dipengaruhi oleh banyak hal, oleh karena itu perlu diidentifikasi faktor-faktor yang menjadi penentu kesuksesan implementasi ini, antara lain: Komitmen manajemen yang kuat dan konsisten dalam keterlibatannya secara langsung sangat membantu mempercepat implementasi, serta peningkatan pemahaman, keterampilan dan pengetahuan sumber daya manusia melalui training.

\section{Kesimpulan Dan Solusi}

Beberapa hal dapat disimpulkan sebagai hasil dari penelitian yang dilakukan pada Yayasan Pendidikan Rosma (Yaperos) berdasarkan tahapan pekerjaan pemodelan Enterprise Architecture sebagai berikut :

1. Penelitian memfokuskan pada pemodelan arsitektur enterprise terhadap aktivitas bisnis Yayasan Pendidikan Rosma (Yaperos) dengan lingkup pemodelan bisnis, data, aplikasi dan teknologi.

2. Arsitektur aplikasi saat ini menggunakan platform yang berbeda-beda, sehingga harus dilakukan penggantian secara keseluruhan untuk menjamin integritas SI yang akan dibangun. Enterprise architecture yang terbentuk bisa digunakan sebagai panduan pengelolaan SI di Yayasan Pendidikan Rosma (Yaperos).

3. Cetak biru (bluePrint) yang dihasilkan dari perencanaan enterprise arcitechture yang menggunakan kerangka kerja TOGAF ADM merupakan perencanaan terperinci dari arsitektur bisnis, data, aplikasi dan teknologi.

\section{Daftar Pustaka}

Bernard, S. A., (2005),. An Introduction to Enterpprise Architecture EA3 ( $2^{\text {nd }} E d$.), United State of America: Author House.

Hadiana, Ana (2016). Perencanaan dan pengembangan Sistem Informasi Terpadu, Megatama, Bandung, 2016.

Kustiyahningsih, Y. (2013). Perencanaan Arsitektur Enterprise Menggunakan Metode Togaf Adm. Prosiding Seminar Nasional Manajemen Teknologi XVIII, ISBN : 978-602-97491-7-5.

Minoli, D., Enterprise Architecture A to $Z$. (2008) Parkway NW: Auerbach Publications.

Rahayu, S. (2015). Perecanaan arsitektur enterprise sistem informasi akademik menggunakan framework togaf, Jurnal Algoritma Sekolah Tinggi Teknologi Garut ISSN : 2302-7339 Vol. 12 No. 1 2015.

Setiawan Budi, Erwin (2009). Pemilihan Ea Framework, Prosiding SNATI, ISSN: 1907-5022, (Institut Teknologi Telkom, Bandung), B114-B19.

Supriyana, Iyan (2010). Perencanaan Model Arsitektur Bisnis, Arsitektur Sistem Informasi Dan Arsitektur Teknologi Dengan Menggunakan TOGAF: Studi Kasus Bakosurtanal, Prosiding Jurnal Generic, ISSN: 1907-4093, (Bakosurtanal, Jawa Barat), Vol. 5 No.1.

The Open Group. (2009). The Open Group Architecture Framework: Architecture Devlopment Method, diakses pada tanggal 22 Februari 2017 dari http://pubs.opengroup.org/architecture/to gaf9-doc/arch/

Yunis, R., Surendro, K. (2009). Pemilihan Metodologi Pengembangan Enterprise Architecture untuk Indonesia. Prosiding SNIKA. Vol. 3, No.1:pp A53-A59. ISSN: 1907-5022 Yogyakarta, 20 Juni 2009 